\title{
Prevalence of gastrointestinal helminthes in Cattle and buffaloes in Bikaner, Rajasthan, I ndia
}

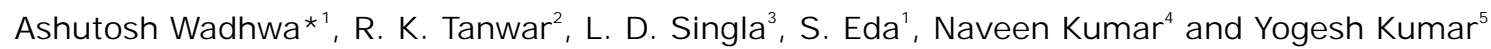 \\ 1. Center for Wildlife Health, Department of Forestry, Wildlife and Fisheries, the University of Tennessee, \\ Knoxville, Tennessee 37996, USA, 2. Department of Veterinary Epidemiology \& Preventive Medicine, College \\ of Veterinary and Animal Science, Rajasthan University of Veterinary and Animal Sciences, Bikaner, \\ Rajasthan, India, 3. Department of Veterinary Parasitology, College of Veterinary Science, Guru Angad Dev \\ Veterinary and Animal Sciences University, Ludhiana, Punjab, India, 4. Department of Pathology and \\ Laboratory Medicine, Emory School of Medicine, Atlanta, Georgia 30332, USA, 5. Central Institute of Post- \\ Harvest Engineering and Technology, PAU campus, Ludhiana, Punjab, India \\ * Corresponding author email : ashutoshwadhwa@gmail.com
}

Received: 18-04-2011, Accepted: 21-05-2011, Published Online: 16-07-2011

doi: $10.5455 /$ vetworld.2011.417-419

\begin{abstract}
In the year 2007, a total of 200 faecal samples comprising of 100 samples each from cattle and buffaloes from different locations of Bikaner, Rajasthan were analyzed to confirm the presence of gastrointestinal parasitic infection. Twenty four $(12.00 \%)$ samples were found positive for strongyle eggs. Eleven per cent cattle and 13 per cent buffaloes were found to be positive for gastrointestinal helminthosis. The prevalence in cattle varied from 9.09 to 12.50 in different locations. Prevalence range was slightly higher in buffaloes which ranged between 10.52 to 14.81 . The estimation of EPG count for Strongyle species in cattle range between 200-1000, with an average of 504.00 \pm 245.41 . This range was 200-1400 with an average of $684.61 \pm 350.82$ in buffaloes.
\end{abstract}

Key words: Buffalo, cattle, helminth, prevalence, strongyle, Rajasthan.

\section{I ntroduction}

The annual growth rate of cattle population is only 0.5 per cent as against the expected growth of 1.1 percent for total livestock in India. Factors like diseases, genetic make up, poor nutritional and managemental practices, environmental stress etc. are responsible for the low productivity of our livestock. Among all of these, parasitic infections, mainly those caused by helminths are the major constraints for poor performance of our livestock. Parasitic infestation is a major constraints of livestock and causes great economic loss to dairy industry by way of retarded growth, low productivity and increased susceptibility of animals to other infections (Yadav et al., 2004).

Most of the economic losses are due to subclinical effects and although not immediately noticed by the owners, these can be substantial. The most complicated part of developing an efficient strategic deworming program for most dairy farmers is being able to understand the natural occurrence of these parasites in dairy animals. Economic losses are caused by gastrointestinal parasitism are in a variety of ways: they cause losses through lowered fertility, reduced work capacity, involuntary culling, a reduction in food intake and lower weight gains, lower milk production, treatment costs, and mortality in heavily parasitized animals (Lebbie et al., 1994) Chowdhury and Tada (1994) described the prevalence and other factors associated with helminthes of domestic animals in Indian subcontinent causing parasitic gastroenteritis. In this study, the incidence of gastrointestinal helminth parasites in cattle and buffaloes (one hundred each) from five destinations around Bikaner District in Rajasthan have been documented.

\section{Materials and Methods}

In the present study faecal samples of 100 cattle and 100 buffaloes from five destinations around Bikaner were collected to know the prevalence of gastrointestinal helminthosis in these animals during the year 2006-07. The faecal samples collected directly from the rectum of individual cattle and buffalo after gross examination for consistency, colour and for presence of any adult worms were processed and screened by direct smear method, Willi's floatation and sedimentation techniques. The ova of parasites were identified from their morphological features (Soulsby, 1982). Quantitative examination of faeces was conducted to record the intensity of parasitic infestation (EPG) by McMaster's technique. The quantum of infection among the animals was derived in terms of percentage positive of the total samples examined. 
Prevalence of gastrointestinal helminthes in Cattle and buffaloes in Bikaner, Rajasthan, India

Table-1. Prevalence of gastrointestinal helminthosis in cattle and buffaloes

\begin{tabular}{llllll}
\hline S No. Area & $\begin{array}{l}\text { Cattle Prevalence (\%) } \\
\text { (Examined/positive) }\end{array}$ & $\begin{array}{l}\text { EPG Range } \\
\text { (Mean } \pm \text { SE) }\end{array}$ & $\begin{array}{l}\text { BuffaloPrevalence (\%) } \\
\text { (Examined/positive) }\end{array}$ & $\begin{array}{l}\text { EPG Range } \\
\text { (Mean } \pm \text { SE) }\end{array}$ \\
\hline 1. & Bangla Nagar & $11.50(26 / 3)$ & $400-1000(666.67 \pm 305.50)$ & $14.28(14 / 2)$ & $500-1100(800.00 \pm 424.26)$ \\
2. & Poogal Road & $12.50(24 / 3)$ & $300-800(600.00 \pm 264.57)$ & $10.52(19 / 2)$ & $600-800(700.00 \pm 141.42)$ \\
3. & Sarvodya Basti & $9.09(22 / 2)$ & $300-500(400.00 \pm 141.42)$ & $14.28(21 / 3)$ & $200-1000(633.34 \pm 404.14)$ \\
4. & Rampura Basti & $11.11(18 / 2)$ & $350-400(375.00 \pm 35.35)$ & $10.52(19 / 2)$ & $500-600(550.00 \pm 70.71)$ \\
5. & Patel Nagar & $11.00(10 / 1)$ & 200.00 & $14.81(27 / 4)$ & $200-1400(725.00 \pm 537.74)$ \\
& TOTAL & $11(100 / 11)$ & $200-1000(504.00 \pm 245.41)$ & $13(100 / 13)$ & $200-1400(684.61 \pm 350.82)$ \\
\hline
\end{tabular}

\section{Results and Discussion}

Prevalence of gastrointestinal helminthosis in cattle and buffaloes: Faecal examination of 100 cattle and buffaloes each during the year 2006-07 revealed 11 per cent cattle and 13 per cent buffaloes to be positive for gastrointestinal helminthosis. Table 1 shows the prevalence and quantitative estimation of parasitic ova at various destinations during the study. The prevalence in cattle varied from 9.09 to 12.50 in different locations. Prevalence range was slightly higher in buffaloes which ranged between 10.52 to 14.81. The estimation of EPG count for Strongyle species in cattle range between 200-1000, with an average of 504.00 \pm 245.41 . This range was 200-1400 with an average of $684.61 \pm 350.82$ in buffaloes. Grossly, adult worms were not found in the faeces of both the species of animals. The faeces were firm in consistency. No clinical signs of worm infestation were found in these animals. Only Strongyle species eggs were detected in faeces. No eggs of other helminthes were seen. This observation corroborates with the earlier findings of Godara and Manohar (2004) who reported higher incidence of Strongyle sp. in cattle of Rajasthan. Similarly Kashyap et al. (1997) reported 40.3 per cent prevalence of gastrointestinal helminthosis in cattle and buffaloes from Madhya Pradesh with prominent infection of Strongyle. Haemonchus spp. was the predominant nematode strongyle reported in buffalo, while Heamonchus and Mecistocirrus spp. was the least in cattle as reported by Sanyal and Singh, 1995.

Jagannath et al. (1988) reported 36.25 per cent of incidence of gastrointestinal helminthosis in cattle and 42.12 per cent in buffaloes in Karnataka. However, more than 50 per cent incidence of parasitic infections in cattle and buffaloes has also been recorded from Gujrat (Pethkar and Hiregaudar, 1972), Haryana (Chhabra et al. 1978), and Rajasthan (Godara and Manohar. 2004).

The onset and advancement of monsoon rains have a profound effect on the incidence and seasonality of fasciolosis in India. Most of the available information on the prevalence of $F$. gigantica comes from abattoir surveys and coprological studies on animals visiting clinics, and is thus biased. It is, however, apparent that the prevalence of fasciolosis in a tropical country like India is largely determined by rainfall and production systems (Copeman and Copland, 2008). Perhaps dry climate of Bikaner with very high temperature and very low rainfall might have produced the unfavorable conditions for the development of the parasites and contributed for keeping low profile of parasitic infection in this area. The rate of prevalence and intensity of various gastrointestinal parasites are severely affected during drought conditions (Chauhan et al. 1981).

In the present investigation the faecal samples were taken from the areas where the animals were reared under good managemental conditions in small units. A higher level of parasitism in dairy cattle has also been reported by Yazwinski and Gibbs (1975), in poorly managed farms in comparision to fairly well managed farms.

Low prevalence of gastrointestinal helminthosis in present study could be due to the fact that deworming of cattle and buffaloes is done by field veterinarians and para-vet staff.

\section{Acknowledgements}

We wish to thank Dr. A.K. Gehlot (Honorable, Vice- Chancellor, Rajasthan University of Veterinary and Animal Sciences, Bikaner), Dr. Fakhruddin, Dr. Anju Chahar, Dr. D. K. Bihani, Dr. A.P. Singh, Dr. Anil Ahuja and Dr. T. K. Gehlot (College of Veterinary and Animal Sciences, Rajasthan University of Veterinary and Animal Sciences, Bikaner) for their guidance throughout the study period. We would also like to acknowledge the funding provided by the Indian Council of Agricultural Research, New Delhi in the form of Junior Research Fellowship.

\section{References}

1. Chauhan, P.P.S.; Bhatia, B.B.; Katara, R.P. and Agarwal, R.D. (1981). Epidemiological survey of common parasitic infections in crossbred cattle. Indian Vet. Med. 5: 108-117.

2. Chhabra, M.B.; Sharma, M.L.; Tikaram, S.M. and Chawla, S.K. (1978). An outbreak of bovine Trypanosomiasis and gastrointestinal parasitism in a flood affected district of 
Haryana. The Haryana Vet. 17(2): 116-120.

3. Chowdhury, N. and Tada, I. (1994). Helminths of domesticated animals in Indian subcontinent, In: Helminthology. Springer-Verlag, Narosa Publishing House, pp. 73-120.

4. Copeman, D., and R. Copland, (2008). Importance and potential impact of liver fluke in cattle and buffalo. In: Gray, G., R.Copland, and D.Copeman (Eds), Overcoming Liver Fluke as a Constraint to Ruminant Production in South-East Asia, ACIAR Monograph no.133, pp. 21-25. ACIAR, Canberra, Australia.

5. Godara, R. and Manohar, G.S. (2004). Prevalence of Gastrointestinal parasitism in different breeds of cattle of Rajasthan. Indian Vet. Med. J. 28: 74.

6. Jagannath, M.S.; D'souza, P.E. and Abdul Rahman, S. (1988). Gastrointestinal parasites of cattle and buffaloes in Bangalore and Mysore Milk Unions. Mysore, J. Agric. Sci. 22: 91-96.

7. Kashyap, Z.; Sisodia, R.S. and Shukla, P.C. (1997). Incidence of gastrointestinal parasites in cattle and buffaloes in Malwa region of Madhya Pradesh., Haryana Vet. 36: 34-36.

8. Lebbie S.H.B., Rey B. and Irungu E.K. (1994). Small ruminant research and development in Africa, Proceedings of the Second Biennial Conference of the African Small Ruminant Research Network, ILCA (1994), pp. 1-5.

9. Pethkar, D.K. and Hiregoudar, L.S. (1972). Helminthic infections of cattle and buffaloes in Gujarat state. Gujarat Vet.(6): 30-31.

10. Sanyal P.K. and Singh D.K. (1995). Proceeding of workshop on control strategy against gastrointestinal parasites in dairy animals using medicated urea moll assess blocks. National Dairy Development Board, Anand, India Pp. 47.

11. Soulsby, E. J. L. (1982): Helminths, arthropods and protozoa of domesticated animals. 6th Ed. CLBS and Bailliere Tindal. pp. 788.

12. Yadav, Anish, Khajuria, J.K. and Raina, A.K. (2004): J. Vet. Parasitol. 18: 167-169.

13. Yazwinski, T.A. and Gibbs, H.C. (1975). Survey of helminth infections in Maine dairy cattle. Am. J. Vet. Res. 36: 16671682 